\begin{tabular}{|c|c|}
\hline Title & Memory talk and testimony in children \\
\hline Author(s) & Naka, Makiko \\
\hline Citation & $\begin{array}{l}\text { Handbook of East A sian Psycholinguistics, v. 2: Japanese, edited by Mineharu Nakay ama; Reiko Mazuka; Y asuhiro } \\
\text { Shirai, I ISBN: } 9780521833349, \text { pp.123-129 }\end{array}$ \\
\hline Issue Date & 2006 \\
\hline Doc URL & http:/hdl.handle.net/2115/44742 \\
\hline Rights & () Cambridge University Press \\
\hline Type & bookchapter \\
\hline Note & Part I: L anguage A cquisition: 1. Ontogeny of language Nubou Masataka. 17. \\
\hline File Information & HEAP2_123-129.pdf \\
\hline
\end{tabular}

Instructions for use 


\title{
17 Memory talk and testimony in children
}

\author{
Makiko Naka
}

Crimes, traffic accidents, street fights, and school bullying: there are many situations in which children are involved and later required to report what happened. They could be victims, bystanders or offenders, but in whichever case, they are typically interviewed by adults (parents, teachers, and police officers) and, in extreme cases, are required to testify before a judge. Such situations yield a rich field where real-world concern and psycho- and sociolinguistic interest meet. From the real-world viewpoint, it is urgent to establish formal guidelines for interviewing children as well as procedures for assessing the reliability of testimony. From the psycho- and sociolinguistic viewpoint, the circumstances raise a range of questions on how children describe their past experience, what linguistic factors affect the amount and accuracy of testimony, how children cope linguistically with interrogation and crossexamination, and what the nature of adult-child communication is like.

The aim of this chapter is to provide readers with an up-to-date account of Japanese studies on how children talk about past events in daily life and in court. We will first show the studies on memory talk in general, and then studies conducted in a forensic context, including studies on witness testimony. In doing so, we will show that children's competence in remembering and describing past events, an important aspect of verbal ability, is embedded in a sociolinguistic context.

\section{Memory talk on past events}

\section{Development in description of past events}

Uehara (1998) made a longitudinal study of verbal reporting on past events in seven toddlers aged 1 to 4 years by visiting them every two months. She found the children started to talk about past events at around the age of 2 to 3 . The early reports are, however, rather fragmented and are only understood by those who are familiar with the context. For instance, a child said "grapes" when looking at a picture of candy. Only the mother could construe it as memory of visiting his grandmother and having grapes together. Interestingly, at that 
stage, children's recounting of "past events" is not necessarily based on facts. They report what could hardly happen ("I saw a whale in a pond nearby"), what might be a source confusion ("I went there," when watching a TV program showing a place the child had never been), and a mixture of unrelated facts ("I lost it because Dad got angry," when the child lost something for other reasons). The results suggest that one needs to acquire not only the language to describe past events (e.g. past tense) but also the knowledge on what a "past event" is: a past event is a fact that actually took place at a certain point in time and place.

However, it is not that simple. In order to study children's comprehension of imagined beings, Sugimura and her colleagues asked preschoolers whether or not they had seen or played with imagined beings such as Santa Claus, a ghost, and an animation character ("Have you ever seen Santa Claus?") (Sugimura et al., 1994). If they said "yes," they were asked "how, where, when." If they said "no," they were asked "why." Surprisingly, 40 percent of younger children said they had seen or played with imagined beings, and gave specific description of the "event" ("I saw a ghost in my house yesterday. It was scary.") Children could tell a fictitious story using the past tense referring to a specific time and place.

\section{Memory talk and scaffolding}

How do children begin to recount facts? Parents seem to have a large role. Takahashi (1995) studied mother-child communication in a televised story. After showing a film to the children only, he instructed the mothers to ask their children what they saw. It was observed that the mothers used prompts to elicit information and asked many questions. He noted that the mothers were selective in gathering information, as they asked for the very information that they needed to understand the event for themselves.

Jin and Naka (2002) studied memory talk between Chinese parents and their children of 2 to 4 years old. From each triad, mother-child talk and father-child talk on recent happy events was obtained. The conversations were transcribed and analyzed in terms of amount of speech (idea units, number of characters, etc.), utterance type (yes/no questions, wh-questions, tagged-questions, directives, etc.), function of utterance (confirmation, elaboration, control of speech, etc.), and content (time, place, people, action, object, emotion). It was found that parents of younger children asked more questions, especially yes/no questions on actions and objects. Contrary to the results from western studies (e.g. Haden, Haine \& Fivush, 1997), sex difference in communication style was found between mothers and fathers. Fathers made more confirmation and directives, and asked more questions especially to 4-year-olds, suggesting that they are less tuned to their child's linguistic level. However, on the whole, the findings 
support the notion of scaffolding: adults reduce their assistance as children become more skillful in memory talk.

The scaffolding is even implemented in the educational system. Fujisaki and Muto studied seikatsu happyo, a classroom practice whereby a child presents her/his recent experience in front of classmates (Fujisaki \& Muto, 1985). Typically, seikatsu happyo is scheduled on a Monday. A teacher invites a child to talk about her/his experience on Sunday, by asking "Does anyone want to tell the class what happened yesterday?" Fujisaki found that for younger children, teachers accepted any topic ("tell us what you did yesterday"), while for older children, they helped them select a specific topic that is worth telling to others ("You went to a camp, didn't you?"). Besides selection of topics, teachers helped children construct their story, by guiding them with such questions as "where did you go?" and "who else came with you?"

Our speculation is that such practice is related to formal education in sakubun, report/essay writing. Elementary school children are frequently assigned sakubun on their experiences on field trips, sports day, school festivals, and so on. In writing, they are encouraged to focus on a specific aspect of the event and to describe it in detail. How they felt about the event is an important element to be included. Such practices may help children learn how to convey the events more effectively as well as what aspects of the events should be encoded as memory.

\section{Children's testimony}

Recently, it has become more common that cognitive psychologists are called in to court to give an expert testimony. It may be characteristic of a Japanese court that they are expected not only to provide general information such as children's linguistic competence and ability to testify, but also to assess a specific testimony in question. The situation has motivated psychologists' research into children's testimony in both laboratory and naturalistic settings. Although the area is still new and underdeveloped, it seems to be promising. In the next section, we will present some laboratory-based studies and naturalistic field studies.

\section{Laboratory studies}

Post-event information effect. Mori and his colleagues studied post-event information effect on preschoolers' memory of events (Mori, Sugimura \& Minami,1996). They first showed a series of pictures depicting a burglar stealing a necklace (typical object: $\mathrm{H}$ ) and a pair of slippers (atypical object: $\mathrm{L}$ ). Later, the protagonist's mother says she cannot find a pendant (typical but not stolen object: h) and a broom (atypical and not stolen object: 1 ), which were to serve as post-event information. The children took a recognition test either 
immediately after the event or after a ten-week interval. The results showed younger children were more suggestible than older children. Furthermore, typical but not stolen objects were erroneously recognized as "stolen" even in the immediate condition, whereas atypical stolen objects were discerned as "not stolen" even after ten weeks, suggesting a post-information effect is greater when it conforms to a schema.

Kikuno (1993) examined post-information effect with second- and fifth-grade children. He showed a series of pictures depicting a boy and a girl having a fight with a toy shovel, and then asked questions that included either original or misleading information. Finally, children were given free recall and recognition tests and a source monitoring test. Both the second- and fifth-grade children were misled into believing they saw post-event information in the original pictures.

The results from experiments show Japanese children are no less susceptible to misleading information than western children. In fact, reviewing the real cases that appeared in hanrei jiho (periodical judicial case reports), Naka found some where post-information might have affected children's testimony (Naka, 2000a). For example, in one case, a child reported to her mother she was molested by a "man who came this morning." However, after she heard her mother say "no one came this morning, it should be yesterday morning," she began to describe the man as "the man who came yesterday morning." In another case where a fourth-grade child accused a "foreign-looking" man of molesting her, it was found that she had had a conversation with classmates beforehand. In the conversation, a girl said to her "I was chased around by a foreign-looking man." The child witness's description of a "foreign-looking man" might have been affected by her classmate's words. In both cases, the children's testimonies were determined as unreliable and defendants were dismissed.

Resilience to post-event information. Is there any way to make memory more resilient to subsequent information? Butler, Gross, and Hayne (1995) have shown that preschoolers who drew a picture as the first description of the event (FDE) later recalled the event better than those who only told what happened as FDE. Inspired by this research, Naka (2000b) tested the effect of FDE on subsequent recognition memory of an event. Second- and fifth-grade children watched a film and were asked to give FDE either by writing (condition 1), imaging and writing (condition 2), answering leading questions (condition 3), or a proper interview (condition 4). They then took a final recognition test, in which they were given twenty scenes and asked to judge whether or not they saw those scenes. Fifteen scenes were false and five were true. In the results, younger children yielded more false recognition than older children. However, the practice of writing the event as FDE (condition 1) reduced the false recognition by approximately 30 percent compared to conditions 2 and 3 . 
Writing might help children retrieve and organize their memory in their own words and from their own perspective, which in turn might make the memory more durable against false scenes.

Laboratory studies provide us with basic knowledge. However, it is also necessary to pay attention to how children in a real situation testify about a past event. Otherwise, we will only accumulate knowledge that may have nothing to do with the real world. In the following, we will report a simulational experiment based on a real case and the studies of interview transcriptions.

\section{Field studies on children's testimony}

A simulational study. The Kabutoyama case is known as a significant miscarriage of justice. A student at a boarding school for mentally handicapped children in Kabutoyama was found dead in a manhole behind a school building. A teacher was accused of murder based on eyewitness testimony by children, saying that she dragged the boy down a hallway. Those children first denied seeing such a scene but after countless interviews which took almost three years, they began to give a rich and detailed testimony.

Takaoka and her colleagues conducted an experiment based on this case (Takaoka et al., 2002). In a preparatory session, a young woman called Takachan visited a nursery school every day for a week. She played with the children and became familiar with them. One day, a young boy called Go-kun visited the nursery school. He spent a few hours with the children but disappeared when children watched a video. Actually, Go-kun's grandfather took him out of school.

Three pairs of undergraduate "investigators" interviewed the children five times over a period of three months. The interviewers did not know what had happened. Although the children did not actually see the boy being taken away by his grandfather, they eventually produced a story, saying the boy went out of the room by himself. The story might have been prompted by the principal's incidental question to a child, "Did he go out by himself?" At first, the interviewers were confused, as shown by one of them saying "Every child tells a different story. I cannot tell which is the truth and which is not." However, by the third interview, they reached a consensus, which included false information. The study suggests that children's testimony could be formed into any direction by intended and unintended questions.

Was this what happened in the Kabutoyama case? It would be elucidating if we could compare the results from the experiment with the real interview conducted by police officers and prosecutors. A problem in Japanese investigative procedures is, however, that interviews are not usually recorded in objective ways such as tape and/or video recording. Instead, police officers and prosecutors make a report from memory in narrative form, summarizing questions and 
answers. Thus, we will never know how the children answered what types of questions.

Analyses of real cases. Ohashi and Mori (2002) examined the communication pattern of one of the child witnesses in the Kabutoyama case. Because of the problem just mentioned, they avoided the use of interviews as materials but used the child's testimony in court, which was literally transcribed. They found that the child freely changed his answers to the interrogator's questions. For example, he gave completely opposite answers when the same questions were repeated. In another situation, the child couldn't answer a wh-question but when it was narrowed down to a yes/no question, he said "yes." Ohashi concluded that the testimony is a sort of collaborative work by the child and the interrogator rather than a narrative based on solid memory.

From a different perspective, Naka (2001) studied characteristics of communication in court, lawyerese. Lawyerese is a language typically used by forensic people and it features multiple propositions ("Do you remember that you saw Anne talking to Bob?"), negatives ("Didn't you see them?"), pronouns and referents, difficult terms, question tags ("You saw them, didn't you?"), and complex syntax (Walker, 1993). Naka examined a transcription of a real case in which a judge, a prosecutor (child's advocate), and a defense attorney questioned a child witness to see whether or not the transcription contained the indices of lawyerese and, if it did, how the child's testimony was affected.

Results showed that the prosecutor was doing pretty well, asking mostly simple wh-questions. However, questions by the judge and especially the defense attorney were complicated and contained a significantly greater number of negatives, pronouns, multiple propositions, and question tags. Accordingly, the child answered the prosecutor with more full answers, while to the judge and the attorney, she responded only "yes" and sometimes gave no answer (i.e. silence, "don't know," "don't remember"). By conflating speakers' responses and matching the questions with each index to answers, it was confirmed that wh-questions were more likely to elicit full answers, while questions with negatives and tags were more likely to elicit only "yes," and questions with complex syntax yielded more silences. The study demonstrated that lawyerese occurs in a Japanese court, and it reduces children's communicability.

One must not overgeneralize the results from case studies. Nevertheless, these studies illustrate a pattern of communication that could be a product of traditional judicial procedures. For example, "one-question (to get) one-answer" is a common way to ask questions in court. Thus in order to pack all necessary information into one question, a question easily becomes syntactically complex with multiple propositions, negatives, and pronouns. Likewise, leading questions (tagged questions) are traditionally welcomed in cross-examination if not in question-in-chief. It would explain why attorneys' questions contain many 
tags. Such a communication pattern is far removed from natural conversation, but nonetheless is a type of communication in the real world.

\section{Summary and implications}

The purpose of this chapter was to review the Japanese research on memory talk and child testimony to show that children's competence in describing past events lies in a sociolinguistic context.

The main findings from the studies are in accordance with those from western studies. Japanese children start to talk about their past events with parents' assistance. They are suggestible, just like western children, as shown in laboratory and field studies. However, there seems to be no direct comparison between Japanese and western children on whether or not there are differences in quantity and quality in memory talk and testimony. Our impression is that Asian children do not speak much to adults compared with western children, which is also suggested from crosscultural studies on narratives (Wang, Leichtman \& Davies, 2000). We do not know at the moment whether this is due to linguistic differences (polite expressions and pragmatic assumptions), educational practices or cultural background. As for the educational aspect, for example, Japanese education puts much emphasis on writing as opposed to speaking, which might be the opposite in western countries. We need crosslinguistic studies through which we are able to understand more clearly how children's competencies and abilities in communication operate under specific conditions. As for application, a range of guidelines and recommendations were developed in North America and Europe, and are already in practice (e.g. Home Office, UK, 1992). By comparison, Japan is far behind, and much effort is needed to improve the situation. 